\title{
Local perceptions in climate change debates: insights from case studies in the Alps and the Andes
}

\author{
Christine Jurt $^{1}$ (D) Maria Dulce Burga $^{2} \cdot$ Luis Vicuña $^{1} \cdot$ \\ Christian Huggel $^{1} \cdot$ Ben Orlove $^{3}$
}

Received: 29 September 2014 / Accepted: 6 October 2015 / Published online: 14 October 2015

(C) Springer Science+Business Media Dordrecht 2015

\begin{abstract}
The importance of integrating local perspectives into international debates about climate change has received increasing attention. Local perspectives on the impacts of climate change often focus on issues of loss and harm and support the widely recognized need for global responses to climate change as suggested by scientists and international institutions. Here we argue that local perspectives need to be addressed not only from outside communities but also from inside in order to understand people's responses to climate change: their concerns, their understanding of themselves as members of particular groups and their position in the world, their view on responsibilities for causing climate change, and their perceptions of possible responses. The ethnographic work at two study sites, one in Carhuaz, Cordillera Blanca, Peru, and one in Stilfs, South Tyrolean Alps, Italy, identifies dominant perceptions on climate change at each site with a particular focus on glacier retreat. The case studies show that the view on the need for global action as response to climate change is not necessarily shared throughout the world, and thus presents a challenge to global collaboration.
\end{abstract}

\section{Introduction}

Global cooperation has been considered to be an indispensable and pressing requirement for an effective response to climate change (Milinski 2014), although there are different views on how to achieve such global cooperation. The great diversity of people concerned with

This article is part of a Special Issue on "Climate Justice in Interdisciplinary Research" edited by Christian Huggel, Markus Ohndorf, Dominic Roser, and Ivo Wallimann-Helmer.

This paper is linked to the following contribution of this special issue: Calder, doi 10.1007/s10584-015-1418-y.

Christine Jurt

christine.jurt@geo.uzh.ch

1 University of Zurich, Zurich, Switzerland

2 Pontificia Universidad Católica del Perú, Lima, Peru

3 Columbia University, New York, USA 
manifold consequences of climate change (IPCC 2014) creates a need for efforts at multiple levels (as for example proposed by Ostrom 2014).

As a step to broaden these efforts we here present an emic perspective and examine how people themselves perceive climate change processes, particularly the retreat of glaciers. This work contrasts with the outside perspective on local issues commonly presented in the international debate on climate change (e.g. Warner and Zakieldeen 2012). We draw on ethnographic fieldwork in two mountain regions in Peru and Italy, and examine how people perceive (1) harm and loss as consequences of climate change, (2) causes of climate change and (3) the responsibilities for responses to climate change.

Deeper knowledge about emic perspectives from different places worldwide is central for the understanding of people's framing of climate change. Such knowledge can clarify the efforts which people take and the level of their effort. Moreover, this knowledge might contribute to an interdisciplinary dialogue as proposed by Castree et al. (2014) aiming at a broad discussion of values that motivate people's behaviour in order to identify regionally and locally diversified approaches to climate change. These diverse approaches, often closely interconnected, can serve as a basis for worldwide collaboration and global responses to climate change.

\section{A few theoretical considerations regarding (global) collective responses to climate change}

Actions and non-actions in response to climate change are widely discussed in the literature. According to Markowitz and Shariff (2012:243f), who draw on behavioural and brain sciences, climate change poses significant challenges to our moral judgement system resulting in a lack of motivation for action. The authors found the following reasons why climate change may not be considered a 'moral imperative': abstractness and cognitive complexity, the blamelessness of unintentional action, guilty bias, uncertainty that breeds wishful thinking, moral tribalism (concerning ideological polarization), long time horizons and faraway places. We argue that underlying the thinking of these challenges are notions of collectivities such as groups that experience impacts, that can(not) be blamed or that exist at faraway places. In this sense, the feeling of belonging to a particular group in a specific position in the world in terms of (political) power or culture, separated by a symbolic boundary from others, becomes crucial for the perception and thus for motivation of possible actions.

To analyse such groups, we draw on the notion of boundaries. Boundaries as used here do not necessarily reflect boundaries between geographic areas as established in natural science studies. Local people draw boundaries themselves, a characteristic widely shared across societies, as discussed by anthropologists and sociologists. Barth (1969), for instance, shows that ethnic groups do not necessarily use a shared culture as the basis for their identity. He shifted the focus from objectively defined cultures to actors' perceptions of group boundaries that distinguish their ethnic groups. In our context, the emic view of establishing, maintaining and representing symbolic boundaries - not necessarily based on ethnic criteria - for distinguishing one's own group from others is important. Lamont and Mólnar (2002:168) define such symbolic boundaries as "conceptual distinctions made by social actors to categorize objects, people, practices and even time and space. They are tools by which individuals and groups struggle over and come to agree upon definitions of reality. [...] Symbolic boundaries also separate people into groups and generate feelings of similarity and group membership." Furthermore, boundaries are not static but dynamic and can change according to 
the actual situation or the course of history (Barth 1969; Pachucki et al. 2007). In this context, we also draw our attention to the notion of boundaries as raised in the area of ethics. Philosophers and legal scholars who discuss morality and ethics recognize that in any concrete situation, responsibility is often attributed to groups or categories of people rather than to individuals. For this reason, boundaries can be traced to decide whether someone is or is not affected by a particular harm, or has contributed to causing that harm.

In this article, we explore local perspectives on how boundaries are drawn between 'we' groups and 'others' around climate change issues, particularly glacier retreat, and analyse them regarding the three aforementioned core issues (1) loss and harm, (2) causes, and (3) responsibilities in the two studied regions in Italy and Peru.

\section{Research methods and sites}

\subsection{Research methods and research sites}

The two study sites (Fig. 1) are situated in high mountain regions near glaciers that are visible from most residents' homes. The municipality of Stilfs is located within the National Park Stilfserjoch in South Tyrol, Italy, at the border with Switzerland. It includes some of the highest glaciated mountains in the Eastern Alps like the Ortler (3905 m above sea level). The municipality of Carhuaz is in the Cordillera Blanca, in the Ancash Region, Peru. Our studies focused on communities within the Chucchún catchment living at altitudes ranging from 2800 to $3600 \mathrm{~m}$ above sea level. The region's highest summit is the Hualcán (6122 m above sea level) with large glaciated slopes.

This article is based on anthropological fieldwork conducted in Stilfs during 7 months between 2003 and 2011 and in Carhuaz during 3 months in 2013. The work was part of two different projects that both focussed on the cultural framing of glaciers. We analysed semi-structured interviews with residents, authorities of the local government and people from organizations working on site. In the municipality of Stilfs, we conducted 54 interviews (female $=16$; male = 38) and 5 group discussions. In Carhuaz and its surroundings, we conducted 67 interviews $($ female $=29$; male $=38$ ) and 7 group discussions. Additionally, we participated in local meetings and collected written material like unpublished historical documents written by residents.

In the interviews, core issues were glaciers, their retreat and their meaning for the population in the past, present and future. Memories reflect how the past is constructed in the present (Nazarea 2006) and are crucial to understanding the changes and variability within a long scale of time (Orlove et al. 2010). The interviews have been coded based on a grounded theory approach and so mostly on inductive coding which is suitable for exploratory work (Russell Bernard 2011). It is important to note that the local perspectives we found at the research sites are as heterogeneous as the local populations. In the following, we focus on widely spread tendencies (within the local perspective at each site) of group boundaries that are constructed around (1) loss and harm, (2) causes and (3) responsibilities.

\subsection{Case study 1: Stilfs, South Tyrol in the Italian Alps}

The municipality of Stilfs counts about 1200 inhabitants. Of these, $98.5 \%$ declare themselves as German speaking and $1.54 \%$ as Italian speaking (ASTAT 2011). The history of the 

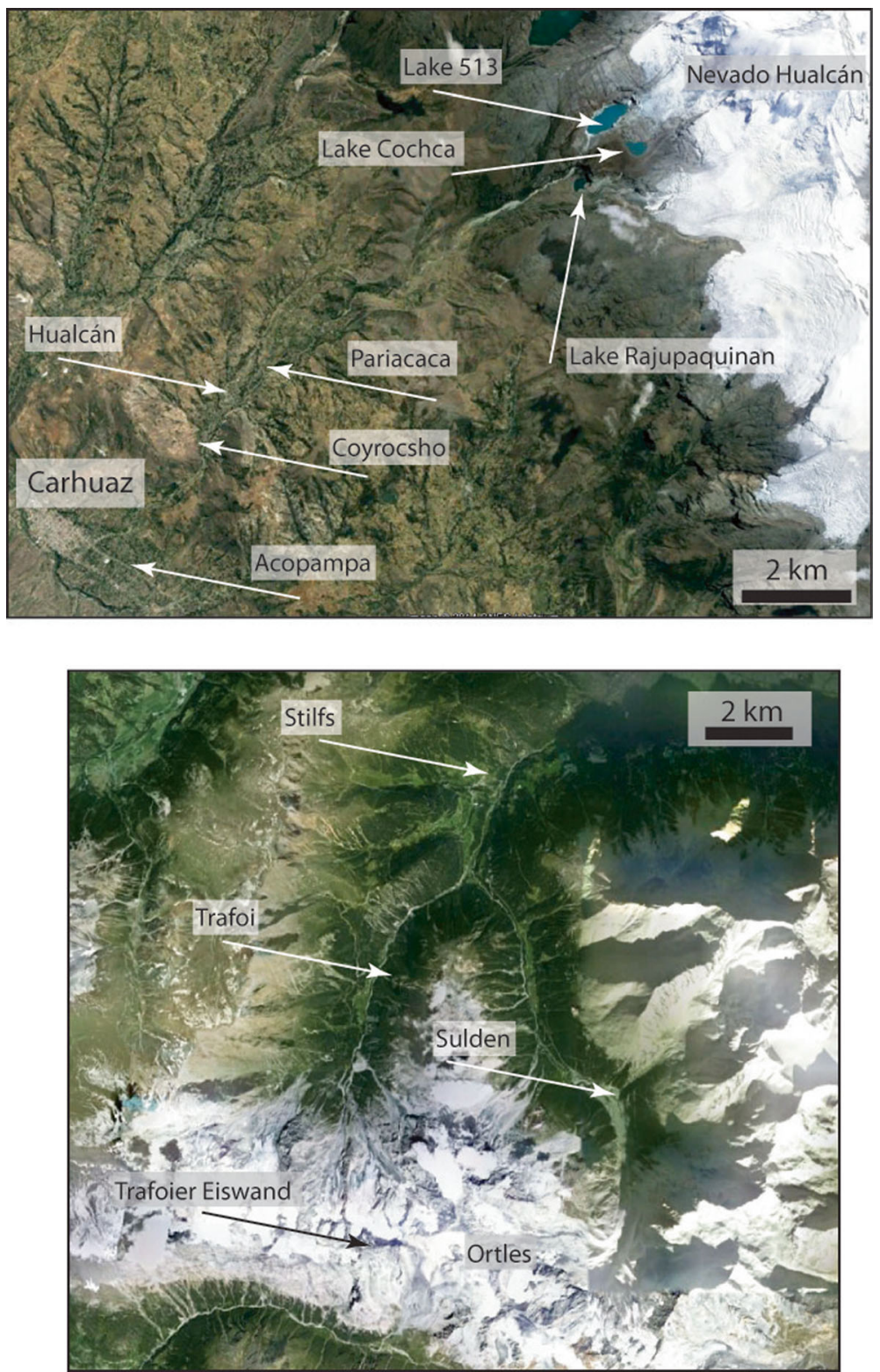

Fig. 1 Map of Stilfs and Carhuaz

municipality is strongly shaped by the political troubles in the 20th century when South Tyrol became part of Italy. Under Mussolini, the inhabitants were given what was called "the option": their stark choice was remaining in Italy, but giving up their culture, or leaving for Germany under Hitler, with the hope of receiving lands in Eastern Europe if Germany won the war. During that time, the municipality was strongly divided into the ones who stayed and the ones who left. For the ones who stayed, tourism provided an important economic basis 
(Kuntner et al. 2004). This importance still prevails, and most inhabitants who work outside tourism need to commute to work outside of the municipality.

Nowadays, tourism is oriented towards family vacationers, hikers, mountaineers, and - near the famous road to the pass Stilfserjoch - towards motorcyclists and cyclists. The glaciated mountains in the surroundings, particularly the Ortler, have attracted tourists from all over the world. The glaciers in the Ortler area have been reported to have shrunk by $23.4 \%( \pm 3 \%)$ between 1987 and 2009, and 21 ice bodies have disappeared entirely (Carturan et al. 2013b) (Fig. 2).

\subsubsection{Emic perspectives in Stilfs}

We start with the retreat of the glaciers to link our argument to harm and loss that the residents experience in relation to climate change. According to a survey about risk perceptions in 2003, the inhabitants of Stilfs perceive retreat and particularly the loss of glaciers as the highest risk in the municipality (Jurt 2009).
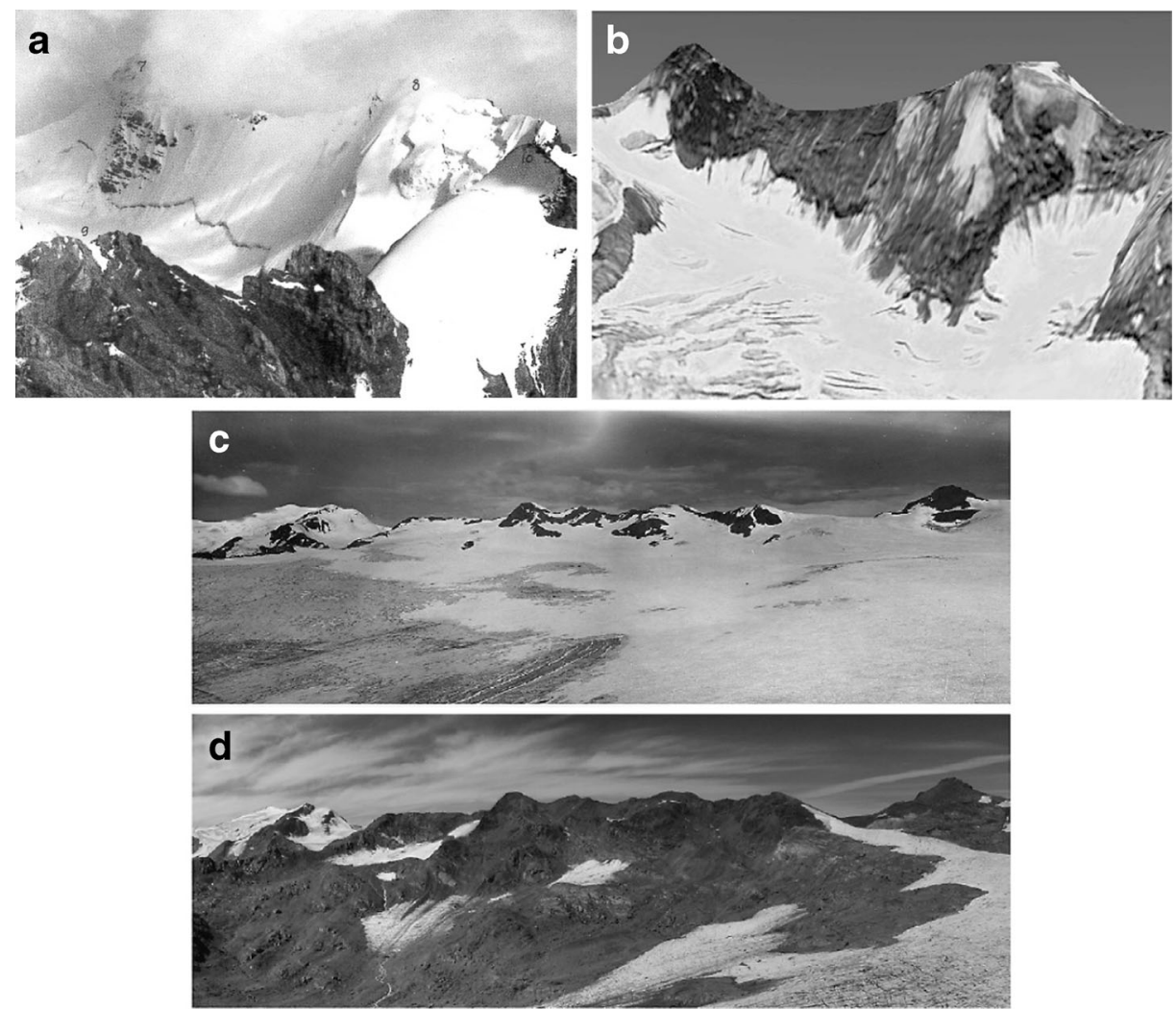

Fig. 2 Decadal glacier change in the Stilfs-Ortler Region. a Trafoier Eiswand, photographed during World War I by the Italian military, as part of a larger panorama (taken from Passarin and Viazzi, 1998). b Trafoier Eiswand, as seen from a visualization of an October 2013 satellite image (obtained from Google Earth). c and d Careser Glacier, some $10 \mathrm{~km}$ southeast of Sulden, in August 1933 (c) and August 2012 (d) (Comitato Glaciologico Italiano and L. Carturan, respectively, from Carturan et al. 2013a). Careser Glacier is one of the well known examples where a glacier has been lost due to climate change 
Glaciers are seen as a major attraction for tourism, and the inhabitants fear strong negative economic impacts on taxes and income accompanying glacial retreat. The feared loss is highly emotional, goes beyond economic terms and is related to cultural values. Glaciers are an archive of memories of the battle sites of World War I and the heroic actions of the local soldiers in the harsh mountain environment (Hurton 2004). The interviews show that glaciers have become an important symbol of a unifying identity helping to overcome the dark time, when the municipality was deeply divided by Mussolini's politics of "the option." The glaciated mountains are the place where the inhabitants feel at home, have survived in politically difficult situations and have managed to build a new promising way of life (Jurt et al. 2015).

This history is questioned by the recent discourse about human-made climate change (e.g. IPCC AR5) that identifies harm and loss as consequences of the inhabitants' lifestyles. They seem no longer a mere legitimate result of a successful survival history. In contrast, interviewees in our study outline different causes and responsibilities, especially natural causes of climate change like the Saharan sand that was brought from far away to the glaciers, lowering the albedo and increasing melt. Furthermore, many interviewees refer to the findings of a scientific study: A tree that was found when the glacier ice melted in Stilfs is seen as evidence that there were warmer periods on site before the Little Ice Age. These findings are regarded as scientific proof of the present changes and are supported by the local history of the glaciers that threatened several local farms (Christomannos 1999). As a conclusion, the present is considered as a climate cycle that will be followed by colder periods again:

'There will be another ice age. We are not going to see it. But for sure, there has always been variability. We think in our time dimension, but nature has a much longer, slower breath. Our life might be one breath of nature, and this [life of nature] will certainly take another course again. [...] For people today, it is not a bright outlook in the short term if the glaciers keep melting. For me, it will last, but for my children, I don't know.' (Male, 39 years)

The quote suggests significant harm for the coming generations that will greatly impact the economy and culture. Action by the municipality government and the inhabitants of the municipality of Stilfs is considered necessary — not to adapt to or mitigate the problem within a long-term, world-wide context but rather to overcome a difficult warm period in the municipality itself.

Nevertheless, causes of glacier retreat are attributed not only to nature but also to the local interactions of people with the glaciers, and so the question of responsibilities comes up:

'What happens when you cross [the glacier] every day over the clean ice? And the dirt?

Such a glacier must die, this is completely normal. [...] But the summer ski resorts are all dying.' (Male, 69 years)

As this quotation shows, some residents believe that the activities of tourists on the surface of the glaciers accelerate their demise. The residents put focus on inadequate local interactions with glaciers - mostly for the purpose of tourism. This argument represents a gap within the community between people working in the tourism business and people having an income independent of tourism. It illustrates a deep ambiguity between the importance of tourism in the short term and the glaciers in the long term. However, the boundaries of who acts in the name of tourism are diffuse, as most residents are linked to tourism by relatives and/or work, and its importance for the municipality remains undisputed. 
A further statement ascribing guilt for harming glaciers is linked to Italian-speaking hoteliers at the Stilfserjoch who are characterised as lacking attachment to nature ('Heimat') and clearly belonging to a group outside of the community. Here, the boundaries are constructed along historical ethnic differences. However, in most interviews, the residents combine multiple causes and even discuss their own contribution to climate change in relation to their global position.

'What can we do when people in China do - God knows what... There is no environmental protection, similarly in America or Russia... [...] Of course, we try at home, we use a wood heating system and not oil. Sure, I think about it, but I do not believe that I, as a single person, can cause climate change.' (Male, 40 years)

This interviewee shifts the group boundary from municipality to the international level (China, America, Russia) back to the single person, to the village and then later on in the interview to South Tyrol as a country in comparison with other industrialized countries. In this context, South Tyrol is presented as a small country whose contribution to contamination or protection is minimal and without relevance. The comparisons are made with countries (political entities) and not with individuals, thus taking away responsibility from one's own lifestyle.

At the same time, ambiguity and uncertainty remain, as the retreat of the glacier still leaves many open questions.

'The glacier is simply power, supremacy of nature. Not as it used to be, but... [...] Supremacy over human beings. First, it is not reachable for many people. And those who can get there feel the mountain and the force of nature much more than others. [...] It is impressive, not accessible, but particularly for children [...] it does not exist in these dimensions anymore. Nowadays, [...] I need to walk a bit and then I see a dirty, noisy ... something. It is not impressive anymore, and obviously my respect for something like this is low.' (Male, 39 years)

People are deeply concerned about the shift from an 'impressive' to a 'dirty something' representing the eroding power of glaciers. Although the boundary between nature and humans remains, the relationship between them is deeply questioned through these processes of glacier retreat, and climate change actions need to be re-considered within the changing context.

\subsection{Case study 2: Carhuaz, Peru, Cordillera Blanca}

The municipality of Carhuaz is characterized by a variety of elevations, climate conditions and vegetation which facilitates different production areas for agriculture, livestock and woodlots. The water from the Chucchún River is essential for agriculture and comes from rainfall, glacier melt and glacial lakes.

The Chucchún catchment was characterized by estates with strong feudalistic aspects until the first half of the 20th century. The land structure underwent changes during the Peruvian agrarian reform in the late 1960s which led to collective land holding and private property. In 1992, the Ministry of Agriculture initiated a program with the goal of creating land titles to increase the land market dynamics, leading to an increasing number of individually owned lots instead of common properties. 
The Chucchún catchment has a history of extreme events such as the ice/rock avalanche from Hualcán in 2010. The avalanche impacted the glacier lake 513, creating a flood which destroyed houses, agricultural land and infrastructure along the riverbanks (Schneider et al. 2014). Nowadays, concerns about new hazards in relation to glacier retreat are increasing. Several non-governmental organisations (NGOs) are present with projects addressing natural hazards and climate change adaptation.

\subsubsection{Emic perspectives in Carhuaz}

Climate change discourse in Carhuaz has led to encounters between different knowledge systems and different worldviews. Many of the interviewed Quechua-speaking farmers have been informed about climate change through workshops by the NGOs as well as through the local schools.

In terms of harm and loss, the most important topic among the residents of Carhuaz is the future of water for personal use and agricultural irrigation. Glacier melt water or in local terms 'the escaping ice' is of high concern. Without glaciers, there will be no water and as a consequence no agriculture. People feel they are about to lose their livelihood as the glaciers are further away and thinner, and their behaviour is increasingly less predictable as evidenced by falling ice blocks. The dimension of this perspective goes much beyond the availability of melting water. Due to political troubles and water scarcity, water conflicts have become severe between different communities. At the same time, the national government has made efforts to introduce new forms of water governance, with new forms of the management of water allocation and with the promotion of a new formal system of laws and regulations.

The interviews show an additional dimension of loss in social and cultural terms as reflected in the residents' memories. In Chucchún, harvesting ice for the production of flavoured ice called 'raspadilla' has been an important source of income but also highly significant for the feelings it evokes of community traditions (Dunbar and Medina 2012). Due to the perceived unpredictable behaviour of the escaping glaciers (expressed through increasing rock and ice falls), today 'raspadilla' is mostly produced from machine-made ice, different in texture and in meaning.

The behaviour of the glaciers roots in human behaviour:

'In earlier times, people from here collected huge amounts of ice to sell it. [..] It was nearby, and this was what affected us mostly. When people started to do that, the 'nevado' [glaciated mountain] started receding. And there is something else, the tourists who come here, who go up there, shatter the ice and the ice starts escaping, starts disappearing.' (Male, 46 years)

At the core of blaming locals and non-locals in this statement lies a local action: a physical encounter between the glaciers and the people which makes the glaciers escape.

This local dimension is strong when contamination enters the discussion. Contamination is a key issue for NGOs and programmes of environmental education in schools through which 'global' information in the form of scientific results about climate change should be brought to the local level. The core cause for glacier retreat is contamination and includes forest fires, changes of concentration of $\mathrm{CO}_{2}$ and aerosols, burning of fossil fuels, land use changes, deforestation, and reflectivity of exposed surfaces.

The argument of contamination is highly present among the local interviewees although it is explained by other processes than those invoked by science. According to the residents, 
contamination is associated with inadequate behaviour and lack of respect which are attributed to local actors.

'You go to the market and buy something, and they give you a plastic bag, and if you don't want to keep it, you throw it on the street. And these [plastic] things have a life that lasts three times longer than a human's life and never go away. I think they are right to tell us that we are the ones who contaminate the world [...], we are the guilty ones, we are going to kill ourselves.' (Male, 55 years)

The citation reflects the discourse of NGOs about the pronoun 'we' referring to humanity or, as used by the resident in the citation above, to the local residents. Contamination here is not restricted to physical processes but encompasses human behaviour towards human beings as well as towards non-humans. Part of the contamination is also linked to the (internationally operated) mines in the surroundings.

'First, I said, this mine [...] is far away from here and from me, too; I said "what kind of contamination should this bring?" They told me that this contamination comes with the wind, with the air [...].' (Male, 43 years)

Although the mining enterprises are perceived as far away, contamination is understood as a local action through the wind and the air although the general actions are ascribed to international actors. Other international actors do personally interact with the glaciers, among them scientists from all over the world researching different topics on glaciers, glacier lakes and natural hazards. Their scientific instruments (i.e. rain gauges) have been seen as casting out the rains. The local population responded by removing the technical equipment, incidents which have been observed in several parts of the Andes (Carey 2010, oral communication in Bolivia).

'I don't know but this ice has a heart. They say that it grows there, and then they wanted to take it from this "nevado", they took it from the Huascarán - as was told-, they took it with them in tubes. [...] Then, back again they wanted to take some from here, but fortunately the lake didn't let them do it. We ourselves took action, there were several who went there for taking and they planted the tubes and wanted to take the heart of the ice with them, sure they know about the nevado's heart. [...] Fortunately, the nevado didn't let them, it didn't want and didn't let them enter [...], it started collapsing, threatening, [...] so they went away [...].' (Male, 46 years)

The citation shows a field of high tension in which several actors are actively involved: scientists, local residents and the glaciated mountain ('nevado') itself. The boundaries are drawn between the scientists (from abroad) and the nevado together with the local population. This clearly-stated example shows that not only humans are actors but also the physical environment - a perception which is distinct from the Western dichotomy between nature and culture (Cruikshank 2005). The relationships between non-humans and humans are central, as the non-humans' forces regulate the relationship with the environment (Paerregaard 2013b). In this sense, glacier retreat is seen as a consequence of incorrect human behaviour that occurred locally. Hence, actions must be taken at the local, not the global level to assure a reaction by the non-human beings. At the same time, these relationships seem increasingly questioned by climate change. Some villagers in Carhuaz argue that glacier retreat is a result of the abandonment of traditional religious practices in which local residents used to make offerings to the 'nevados'. Others, however, are sceptical about this view not at least 
because the power of the non-humans, in our case the escaping glaciers, is increasingly questioned.

\section{Discussion and conclusions}

By comparing the local perspectives at the two study sites and analysing the different framings of climate change and glacier retreat, we find different underlying social boundaries which are crucial for people's actions. Important for the understanding and the construction of these boundaries are the historical dimension and the residents' worldview.

In Stilfs, the tourism perceived as indispensably linked to the glaciers is more than an economic necessity. It is linked to identity and continuity of the community which has survived politically and economically troublesome times, characterized by poverty and suppression, which residents managed to overcome. In Carhuaz, glaciers have played a crucial role in regulating residents' relationship with nature (Paerregaard 2013a), facilitating economic activities (e.g. 'raspadilla'), using meltwater for agriculture and having a strong sense of community continuity.

By examining the group identifications and boundaries that are associated with the core notions of loss and harm, with the attribution of causes of climate change and with the associated responsibilities for damages, it is possible to understand the significance that climate change and glacier retreat have for residents at both sites.

The first three groups at each site specified in Table 1 are closely linked to their local communities whereas groups 4 and 5 represent different levels. In Stilfs, people mention as the fourth group the autonomous province of Bolzano, a political entity which is crucial for the residents' autonomy as well as their identity as a German-speaking minority. The fifth group 'human beings worldwide' is based on the common knowledge of the scientific discourse (e.g. the role of human beings in causing climate change according to the IPCC). In contrast, in Carhuaz, the fourth group refers to the group of farmers - a social rather than a geographically limited category -, and a global perspective is not present, neither for causes nor for responsibilities.

By establishing boundaries distinguishing themselves from others, the residents at both sites define groups which can be understood through moral frameworks - identifying those who cause harm and those who suffer harm. The boundaries between these groups are continuously (re-)constructed depending on the context. Blame is a striking aspect at both sites although the arguments and the groups (the blaming as well as the blamed) differ considerably.

The key arguments show that in Stilfs, the responsibility for causing glacier retreat is mainly ascribed to natural processes. When the residents see a possible contribution by humans, they blame others. These others can be part of a group within the municipality or outside at the national level (Italians) or the international level (residents of other countries receive more blame for higher contamination than the populations of South Tyrol). Whenever a feeling of guilt is reported or humanity is blamed, the argument strongly represents what Markowitz and Shariff (2012:244) call the 'blamelessness of unintentional action'. In this case, one's own guilt disappears in the unintentionality or in the denial of severe impacts and turns into 'wishful thinking' (e.g. overcoming a temporarily difficult decade).

This stands in contrast to Carhuaz, where the residents fully ascribe the guilt to themselves and support their views with claims of institutions from outside (NGOs and governmental 
Table 1 Identified groups and arguments for boundary making

Stilfs

Bounded groups arranged from most local to broadest

1. Residents of the municipality being involved in tourism

2. Residents not involved in tourism

3. Residents of the particular village of the municipality as a whole

4. Residents of South Tyrol

5. Human beings worldwide

Key topics of boundary making

1) Tourism

2) Local actions on glaciers

3) If it really is the case that there is some guilt of human beings...
Arguments for boundary making in Stilfs based on

Local history, scientific studies Nature with its natural climate cycles

Local observations, local history

Economic and political position in terms of power, the right of access to wealth
Responsibility ascribed to

Human beings involved in tourism

Human beings in countries far away, and to a small extent "others" at the local level (people involved in tourism)

Carhuaz

Bounded groups arranged from most local to broadest

1. Residents involved in programmes with NGOs and institutions of the government

2. Residents with low involvement in programmes of NGOs and institutions of the government

3. Residents of the particular sites within the comunidad campesina

4. Campesinos in general (farmers)

Main topics of boundary making in Arguments for boundary Responsibility ascribed to Carhuaz making in Carhuaz

1) Local immoral behaviour

Local history, roles of human beings, of non-humans and nature in the world

2) Contamination

"They [NGOs and
governmental institutions] say so, too."

3) Hidden actions of strangers, Local history, roles of human immoral behavior against non-human and human beings beings, of non-humans and nature in the world
Residents themselves

Residents themselves

Strangers who arrived on site

institutions). In contrast to Stilfs, unintentional consequences are not mentioned, but the residents view themselves as active designers of their environment. This view contradicts the international discourse in which indigenous people are seen as helpless victims of climate change processes (among others Carey 2010; Boillat and Berkes 2013).

The arguments in Stilfs mainly focus on tourism. The importance of tourism as an incomegenerating activity is not questioned, although critical voices in the municipality associate tourism with the alienation of the residents from nature through the change of values that it brings along. In this sense, tourism is ascribed guilt for causing climate change by its impact on human behaviour, and the demand of the tourist is the key (e.g. skiing on the glaciers or water use). If tourism is to flourish, the residents will have to accept the tourists' wishes, and the harm gets a strong unintentional character.

In contrast, the arguments in Carhuaz mainly focus on contamination. The residents underline their collective and individual guilt with the argument of NGOs, who blame the farmers for unsustainable agricultural practices and the villagers in general for littering. 
Underlying their acknowledgement of guilt are the feelings of having behaved in an inadequate way. If they blame outsiders, it is on the basis of local interactions with the glaciers directly or indirectly in the case of the mines - and not because of lifestyles of people at faraway places. Crucial from their perspective is that responses to climate change need to be local and need to integrate the non-humans whose forces impact interactions between the residents and their environment.

Residents in Stilfs put their hope into technology and economic opportunities (including support from outside such as from the European Union) for overcoming the hard period of this climate cycle, or into nature's self-healing in the very long term. Residents in Carhuaz emphasise the need of resolving the problem at their local level based on their own behaviour and protecting non-humans against the immoral behaviour of strangers.

We have shown that local residents at two mountain sites draw multiple boundaries that run across different local, national and international groups or actors as shown in terms of loss and harm, and in terms of the causes of and responses to climate change. These local perspectives can bring new categories of actors into consideration. In particular, the residents of Carhuaz speak of non-human actors (mountains, lakes, winds) whose actions and responsibilities go beyond the broadly applied category of nature-culture. We have found as well that local perceptions rest on worldviews that are based on specific understandings of nature, culture and the universe (including non-human beings) and that have specific concepts of justice that derive from local contexts and histories. These worldviews influence the sense of responsibility and the scope of possible action which local people perceive. This deeper understanding of local perspectives can provide a fuller account both of local actions (and inactions) in response to climate change in the present moment, and can also identify possible future responses to climate change and glacier retreat.

In both the Italian Alps and the Peruvian Andes, the residents of communities which have faced glacier retreat for more than a generation draw on frameworks which differ from dominant scientific and policy perspectives, but it does not seem appropriate to call them 'skeptics' or to simplify their accounts to a contrast between nature and culture, or between local and global scales. Instead, we find that they have complex, nuanced engagements with scientific accounts of climate change, with their place in natural and cultural worlds, and with multiple social and spatial scales. In sum, we argue that a close engagement with local perspectives, such as the one which we have sketched out here, can lead to a reconsideration of some common frameworks in the climate change literature.

\section{References}

ASTAT (2011) Südtirol in Zahlen - Alto Adige in cifre. Südtirol Landesinstitut für Statistik, Bozen

Barth F (1969) Ethnic groups and boundaries. Waveland Press, Illinois

Boillat S, Berkes F (2013) Perception and interpretation of climate change among Quechua farmers of Bolivia: indigenous knowledge as a resource for adaptive capacity. Ecol Soc 18(4):21

Carey M (2010) In the shadow of melting glaciers. Climate change and Andean society. Oxford University Press, Oxford

Carturan L, Baroni C, Becker M, et al. (2013a) Decay of a long-term monitored glacier: careser glacier (OrtlesCevedale, European Alps). Cryosphere 7:1819-1838. doi:10.5194/tc-7-1819-2013

Carturan L, Filippi R, Seppi R, Gabrielli P, Notarnicola C, Bertoldi L, Paul F, Rastner P, Cazorzi F, Dinale R, Dalla Fontana G (2013b) Area and volume loss of the glaciers in the Ortles-Cevedale 
Group (Eastern Italian Alps): controls and imbalance of the remaining glaciers. Cryosphere 7:1339-1359. doi:10.5194/tc-7-1339-2013

Castree N, Adams MW, Barry J, Brockington D, Büscher B, Corbera E, Demeritt D, Duffy R, Felt U, Neves K, Newell P, Pellizzoni L, Rigby K, Robbin L, Rose DB, Ross A, Schlosberg D, Sörlin S, West P, Whitehead P, Wynne B (2014) Changing the intellectual climate. Nat Clim Chang 4:763-768. doi:10.1038/ NCLIMATE2339

Christomannos T (1999) Sulden-Trafoi. Schilderungen aus dem Ortlergebiete. Tourismusverein im Ortlergebiete, Bozen

Cruikshank J (2005) Do glacier listen? Local knowledge, colonial encounters, and social transformation. University of British Columbia Press, Vancouver

Dunbar K, Medina K (2012) Singing for shaved ice: glacial loss and Raspadilla in the Peruvian Andes. In: Sinclair J, Pertierra A (eds) Consumer culture in Latin America, 1st edn. Palgrave Mamillan, New York, pp. 195-206

Hurton J (2004) Sulden. Geschichte, Land, Leute und Berge. Eigenverlag, Bozen

IPCC (2014) Climate change 2014: impacts, adaptation, and vulnerability. Part A: global and sectoral aspects. Contribution of Working Group II to the Fifth Assessment Report of the Intergovernmental Panel on Climate Change. Cambridge University Press, Cambridge, 1132

Jurt C (2009) Perceptions of natural hazards in the context of social, cultural, economic and political risks - a case study in South Tyrol. Dissertation, University of Berne

Jurt C, Brugger J, Dunbar K, Milch K, Orlove B (2015) Cultural values of glaciers. In: Huggel C, Carey M, Clague JJ, Kääb A (eds) The high-mountain cryosphere: changes and risks. Cambridge University Press (in press), Cambridge

Kuntner A, Haringer M, Knoll C, Mayenberger L, Pinggera S, Platzer-Vögeli E, Reinstadler E, Reinstadler P, Reinstadler W, Thöni M (2004) Die Bergführer von Sulden and Trafoi Legende und Geschichte. Raiffeisenkasse, Schlanders

Lamont M, Mólnar V (2002) The studies of boundaries in social sciences. Annu Rev Sociol 28:167-195. doi:10. 1146/annurev.soc.28.110601.141107

Markowitz EM, Shariff AF (2012) Climate change and moral judgement. Nat. Climate Change 2:243-247. doi: $10.1038 /$ nclimate 1378

Milinski M (2014) Modeling a polycentric approach to the problem of climate change. Comment on "Climate change governance, cooperation and self-organization" by Pacheco, Vasconcelos \& Santos. Phys Life Rev. doi:10.1016/j.plrev.2014.07.013

Nazarea VD (2006) Local knowledge and memory in biodiversity conservation. Annu Rev Anthropol 35(1): 317-335. doi:10.1146/annurev.anthro.35.081705.123252

Orlove B, Roncoli, C Kabugo, M., \& Majugu, A (2010) Indigenous climate knowledge in southern Uganda : the multiple components of a dynamic regional system. Clim Chang, 100, 243-265. doi: 10.1007/s10584-009-9586-2

Ostrom E (2014) A polycentric approach for coping with climate change. Ann Econ Finance 15(1):71-108. doi: $10.1596 / 1813-9450-5095$

Pachucki MA, Pendergrass S, Lamont M (2007) Boundary processes: recent theoretical developments and new contributions. Poetics 35:331-351

Paerregaard K (2013a) Bare rocks and fallen angels: environmental change. Clim Perceptions Ritual Pract Peruvian Andes Relig. doi:10.3390/rel4020290

Paerregaard K (2013b) Governing water in the Andean community of cabanaconde, Peru. Mt Res Dev 33(3): 207-214. doi:10.1659/MRD-JOURNAL-D-12-00107-1

Passarin M, Viazzi L (1998) Panorami della Grande Guerra. Sul fronte dallo Stelvio al Garda. Dalle Raccolte della Sezione fotográfica del Comando Supremo del R. Esercito Italiano. Publigrafica Editrice, Tavernelle, Vicenza, $71 \mathrm{pp}$

Russell Bernard H (2011) Research methods in anthropology: qualitative and quantitative approaches. Rowman, Altamira

Schneider D, Huggel C, et al (2014) Mapping hazards from glacier lake outburst floods based on modelling of process cascades at lake 513, Carhuaz, Peru. Adv Geosci 35:145-155

Warner K, Zakieldeen SA (2012) Loss and damage due to climate change: an overview of the UNFCC negotiations. European Capacity Building Initative (ECBI), Oxford 